\title{
An interactive game-based shoulder wheel system for rehabilitation
}

This article was published in the following Dove Press journal:

Patient Preference and Adherence

22 November 2012

Number of times this article has been viewed

\section{Chun-Ming Changl,* \\ Yen-Ching Chang ${ }^{2,3}$ \\ Hsiao-Yun Chang ${ }^{4}$ \\ Li-Wei Chou ${ }^{5,6, *}$}

'Department of Applied Informatics and Multimedia, Asia University, Taichung, Taiwan; ${ }^{2}$ Department of Medical Informatics, Chung Shan Medical University, Taichung, Taiwan; ${ }^{3}$ Department of Medical Imaging, Chung Shan Medical University Hospital, Taichung, Taiwan; ${ }^{4}$ Department of Biotechnology, Asia University, Taichung, Taiwan; ${ }^{5}$ Department of Physical Medicine and Rehabilitation, China Medical University Hospital, Taichung, Taiwan; ${ }^{6}$ School of Chinese Medicine, College of Chinese Medicine, China Medical University, Taichung, Taiwan

*These authors contributed equally to this work
Correspondence: Chun-Ming Chang Department of Applied Informatics and Multimedia, Asia University,

500, Lioufeng Rd, Wufeng,

Taichung 4I354, Taiwan

Tel +886423323456 ext 1853

Fax +88 6423320718

Email cmchang@asia.edu.tw
Background: Increases in the aging population and in the number of accidents have resulted in more people suffering from physical impairments or disabilities. Rehabilitation therapy thus attracts greater attention as a means of helping patients recover and return to a normal life. With the extremely long and tedious nature of traditional rehabilitation, patients are reluctant to continue the entire process, thus the expected effects of the therapy cannot be obtained. Games are well known to help patients improve their concentration and shift their attention away from the discomfort of their injuries during rehabilitation. Thus, incorporating game technology into a rehabilitation program may be a promising approach.

Methods: In this study, a gaming system used for shoulder rehabilitation was developed. The mechanical parts and electric circuits were integrated to mimic the functionalities of a shoulder wheel. Several games were also designed to suit the rehabilitation needs of the patients based on the age and gender differences among the individual users, enabling individuals to undergo the rehabilitation process by playing games. Two surveys were conducted to evaluate the satisfaction of the participants regarding the gaming system.

Results: The results of the online survey among a larger population coincide with the responses of the hands-on participants through a paper-and-pencil survey. Statistical results suggest that the participants are willing to accept this novel approach.

Conclusion: This gaming system can distract a patient from the sensation of pain or anxiety, and increase their motivation to participate in the therapeutic program. Advantages in terms of low-cost and easy setup increase the attractiveness of this new equipment for various potential users.

Keywords: virtual reality, virtual rehabilitation, shoulder wheel, game design

\section{Introduction}

Advances in technology and medical science improve the quality of life as well as reduce the risk of mortality at various life stages. Those who have lost the ability to function normally because of trauma, surgery, stroke, tumor, or infection can regain as well as maintain independence and a good quality of life through rehabilitation. This process focuses on restoring certain functions of a damaged body part or utilizing education to train individuals to compensate for the damage that cannot be repaired. The treatment typically involves continued sessions of one-to-one training for a number of weeks. Severe cases require long-term care, of which the associated demands may pose the greatest challenge for personal, family, and public resources.

Shoulder pain is an extremely common complaint among the general population, accounting for $5 \%$ of all general medical practice consultations. This is the fourth most 
frequent type of musculoskeletal pain reported by patients to general medical practitioners and physical therapists. ${ }^{1}$ Shoulder pain is typically characterized by symptoms in the various joints, muscles, tendons, and bursae involved with shoulder motion. ${ }^{2}$ Such disability of the body affects the person's daily activities and quality of life. Rehabilitation is the key to returning the shoulder to its original state, which is typically accomplished through simple exercises. Shoulder exercises are useful in the treatment of numerous causes of shoulder pain, 3,4 and are performed under the direction of a physician to ensure that the proper muscles are targeted for a specific condition.

Shoulder rehabilitation focuses on two important aspects of shoulder motion: flexibility and strength. ${ }^{5}$ Shoulder mobility is commonly improved through the use of certain types of equipment, such as the shoulder wheel, overhead pulley, and finger ladder, among others, in a range of motion exercises. Serious illness or injury often leads to a long, slow return to health. Regardless of the condition, one of the main keys to recovery is participation. Unfortunately, the treatment procedure is usually tedious, and the patients often do not maintain focus during and throughout the training process. The treatment program typically lasts too long for the patient to keep the therapy plan on track. At times, the patient might not remember if he or she has completed enough exercises. Furthermore, traditional rehabilitation has the disadvantages of an absence of computerized sensing mechanisms, high costs, and an uneven distribution of therapists.

Virtual reality (VR) environments have attracted considerable interest as assistive technologies for rehabilitation. ${ }^{6-8}$ With VR, a player can interact with the computer via a user-friendly interface. The movements made in the virtual environment mimic those made in the physical environment. Compared with classical rehabilitation, the benefits of virtual rehabilitation include economy of scale, stored patient data, remote data access, low health care costs, interactivity, and patient motivation. ${ }^{6,9}$ A VR rehabilitation system typically consists of a computing platform, feedback sensors, and software. Adamovich et $\mathrm{al}^{10}$ used a VR environment in combination with robotic devices to assist in the recovery of hand/arm function. A high-end CyberGlove ${ }^{\circledR}$ component (CyberGlove Systems LLC, San Jose, CA) was used for the sensorimotor training of the hemiparetic hand. ${ }^{11}$ Guberek et $\mathrm{al}^{12}$ evaluated the level of cooperation and satisfaction associated with practicing arm and hand movements for rehabilitation purposes in cerebral palsy.

Several researchers have focused on developing software (computer games) to create VR environments and game frameworks on personal computers (PCs). ${ }^{13,14}$ Most existing VR systems are expensive, heavy, and require frequent technical support. Morrow et $\mathrm{al}^{15}$ reduced the cost of hardware by integrating several low-cost components based on a modified Xbox (Microsoft Corporation, Redmond, RA) gaming system for poststroke hand rehabilitation. ${ }^{15}$ Raichur et al ${ }^{16}$ developed an accelerated stroke rehabilitation platform based on electroencephalography/surface electromyography signals to enable home use. Burke et $\mathrm{al}^{17}$ proposed a low-cost visual tracking system for home-based, upper-limb stroke rehabilitation, without the need for expensive or special equipment, and which could be independently operated by the patient. To avoid development time and costs, the authors ${ }^{18,19}$ used a commercial off-the-shelf product (Nintendo ${ }^{\circledR}$ Wii gaming system; Nintendo Co, Ltd, Kyoto, Japan) to provide VR therapy. The attention required to play a game can distract the player from the sensation of pain. The gaming system not only increases the willingness of patients to accept the treatment, but also increases their comfort during the process. Thus, incorporating game technology into the rehabilitation program seems to be a promising approach.

In general, the strategy of game design for rehabilitation would be considerably different from that of commercial video games. Burke et $\mathrm{al}^{20}$ identified two principles that are significant to game design: meaningful play and challenge. Meaningful play emerges from the interaction between a player's actions and the system's outcomes. Challenge means that a game should be designed to gradually increase in difficulty as it progresses. Ryan et $\mathrm{al}^{21}$ demonstrated the value of an iterative, player-centric game design. Furthermore, Magee $^{22}$ suggested that the game concept requires addictive attributes such as competitiveness, clickability, progressive achievement, rewards, and physical and cognitive challenges, as well as entertainment value. Visual or verbal feedback is similarly significant in game playing.

As of this writing, almost all games on the market have one of seven age suitability ratings set by the Entertainment Software Rating Board. ${ }^{23}$ Potential game players span all age groups, and each age group has its preference of games. The number of makers of computer-based and online video games for the elderly is increasing. The agility of elderly players is not comparable with those of adolescents, and thus the former have their own preferences in terms of game content. The Japanese giant, Nintendo, has developed the "Brain Age" game for its DS game console. ${ }^{24}$ This game features tasks in memory, mathematics, reading, and even music, encouraging players to think by engaging in challenging exercises. Allstate Corporation (Northbook, IL), incorporated with 
Posit Science Corporation (San Francisco, CA), also studied the use of video games to improve the driving ability of the elderly. ${ }^{25}$ Patients in the rehabilitation program might be retained by designing specific games for each age group to increase their motivation to play.

A gender gap exists between males and females in the use of technology. Previously, video game users were mostly males, but that situation has changed since 1996, when Mattel Media (Mattel Inc, El Segundo, CA) launched three video games based on the best-selling toy of all time, Barbie (Mattel Inc). Several studies revealed girls' different preferences in software design, showing that girls preferred multiplayer modes, and also enjoyed playing and communicating with other users. Girls were not interested in violent and exaggerated female sexuality content, and were generally afraid to participate in competitive games. ${ }^{26-29}$ Another study showed that females tended to play card games and chess games, whereas males, by contrast, had a strong competitive tendency, and were inclined to challenge and outdo other players; massive multiplayer online roleplaying games (RPGs) and action games were shown to be male favorites. ${ }^{30}$ The studies further suggested that males spent more time and enjoyed playing more computer games than females. Gender differences also existed in both the frequencies and the types of games played.

In this study, we hypothesize that a game is significant for medical rehabilitation, and that gender and age are two crucial factors in designing a game. In applying video games to medical rehabilitation, the system must provide functionalities similar to those of the existing physical therapy equipment. The system is operated by a patient based on the treatment procedure, as determined and established by a therapist. In this paper, we propose a game-based system for shoulder rehabilitation. A homemade, fully functional shoulder wheel that mimics the functionalities of the existing shoulder wheel was constructed. Six games were designed to fit the specific needs of individuals based on gender and age. Two surveys were conducted to evaluate the satisfaction level of the participants.

\section{Materials and methods Shoulder wheel system}

Figure 1 illustrates the architecture of the shoulder wheel rehabilitation gaming system. The system is composed of hardware implementation and software design. The hardware is comprised of a homemade shoulder wheel and a control module. The software consists of two subsystems: one for management and another for gaming. The former is used by

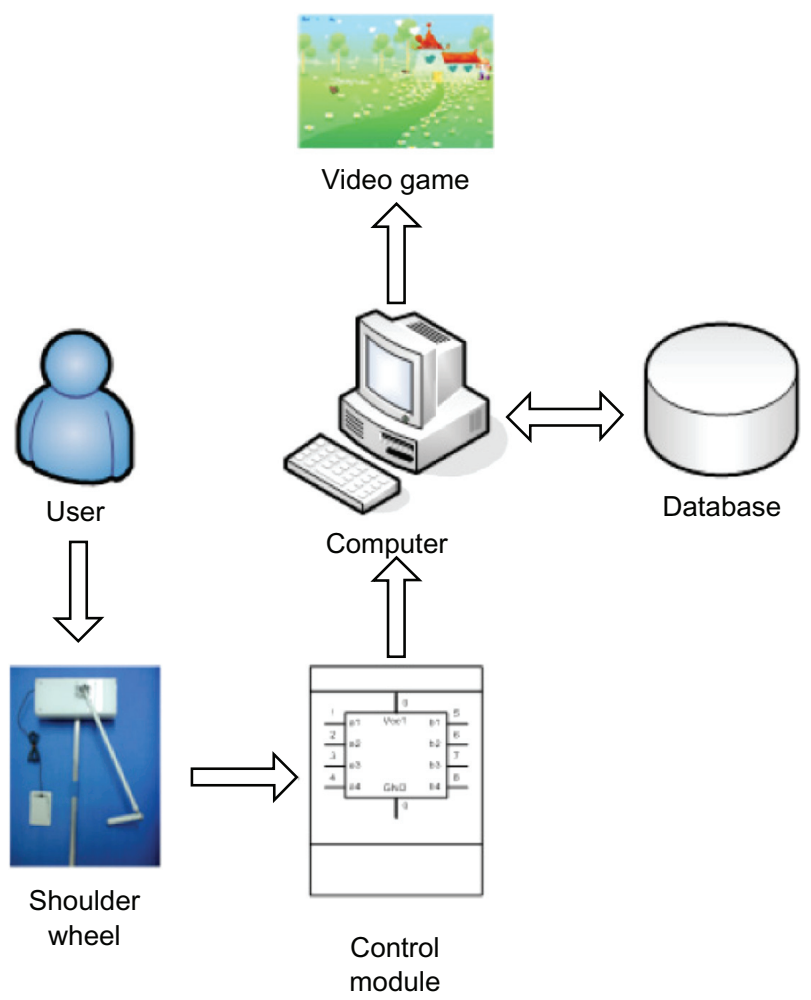

Figure I Proposed system architecture.

a therapist to create an account and to review the treatment process, while the latter serves as a portal through which a patient can begin the treatment.

A shoulder wheel (eg, model 605 by Bailey Manufacturing Company [Lodi, $\mathrm{OH}]$ ) performs circular motions, and, according to its specifications, ${ }^{30}$ the diameter of the tubular circle is 37.5 inches with a height adjustable up to 26 inches, and a handle adjustable to 39 inches of arc. We built a shoulder wheel (axial model) using off-the-shelf materials based on these specifications. The homemade shoulder wheel function is demonstrated in Figure 2A. A control module was also designed to transform the wheel rotation into control signals to trigger a game, as shown in Figure 2B.

The need for rehabilitation crosses all age groups, whereas the type, level, and goals of rehabilitation often differ by age and gender. According to one research report, ${ }^{31}$ players above the age of 30 prefer games of strategy. For those under 18 years of age, massive multiplayer online games are the first choice. RPGs are favored by those in between these age groups. Given the growing number of both old and young players, we extended the age range of the middle age groups on both ends to balance the age distribution. In this study, six computer games were designed according to the age and gender differences noted among users. Three age groups (G1, under 14 years; G2, 14-45 years; and G3, over 45 years) are 

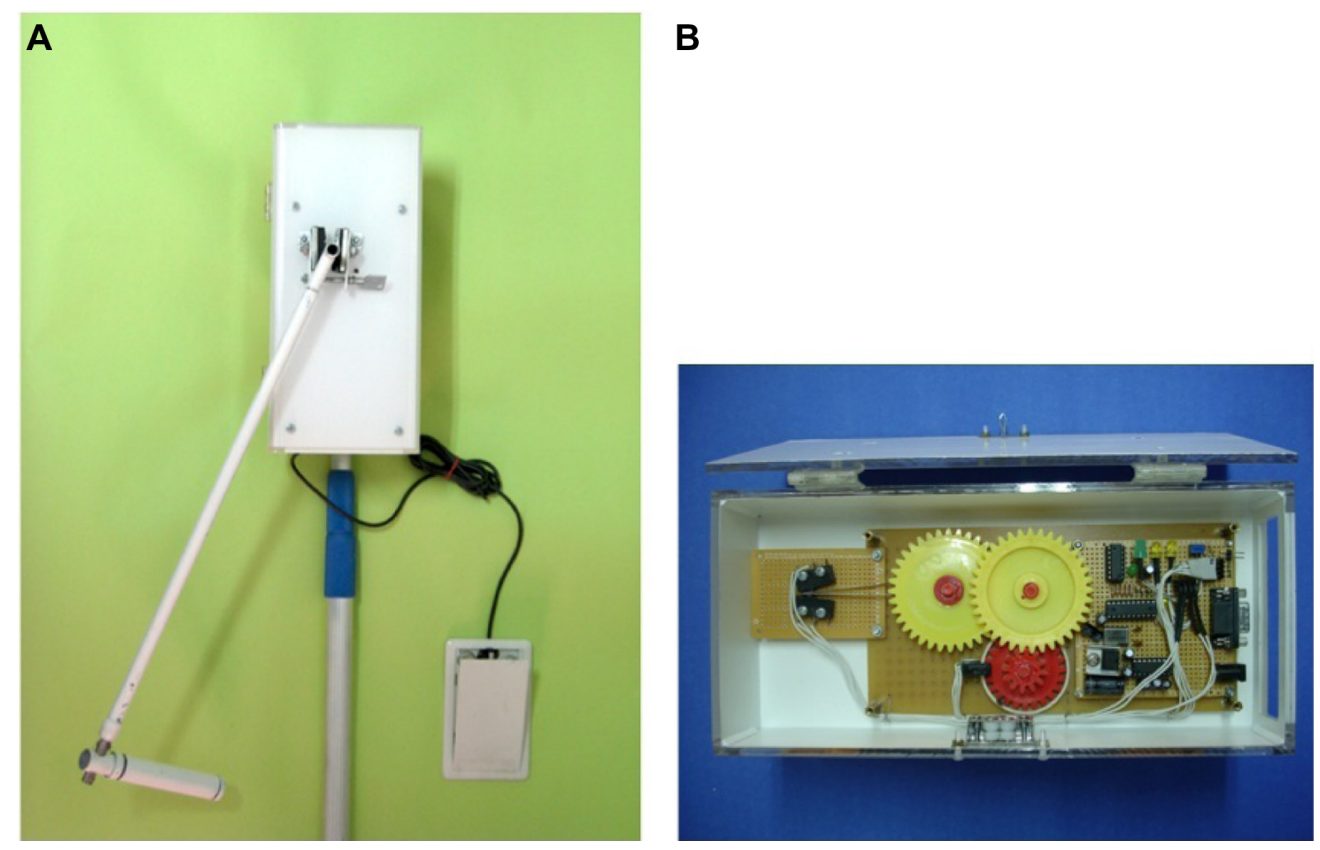

Figure 2 Shoulder wheels. (A) A homemade sample. (B) Interior of the control module.

classified for each gender, and the game title for each group is illustrated in Table 1. Table S1 shows the corresponding descriptions of these games. Figure 3 demonstrates a sample screenshot of our game titled "Cupid's Arrow" for female players between the ages of 14 and 45 .

\section{Study sample and setting}

Our experiments were comprised of two surveys: a paperand-pencil survey, and an online survey. The paper-and-pencil survey was administered among 68 healthy participants distributed across all age and gender groups, and recruited within a specific community. None of the participants had ever used a shoulder wheel, and thus their opinions would not be biased by any prior experience. In the online survey, 531 subjects participated. The website was open to the public, and no restrictions were established for the qualifications of survey respondents.

The setup of our system is described as follows. The software design of the gaming system was implemented using Visual Basic 6.0 on a Windows XP platform (Microsoft Corporation). The rehabilitation games can be played on

Table I Game titles for each group

\begin{tabular}{|c|c|c|c|}
\hline $\begin{array}{l}\text { Group } \\
\text { number }\end{array}$ & $\begin{array}{l}\text { Age } \\
\text { range }\end{array}$ & $\begin{array}{l}\text { Game titles } \\
\text { for males }\end{array}$ & $\begin{array}{l}\text { Game titles } \\
\text { for females }\end{array}$ \\
\hline GI & Under 14 & Submarine Hunter & Cockroach Buster \\
\hline G2 & Ages 14-45 & Trebuchet & Cupid's Arrow \\
\hline G3 & Above 45 & Treasure Chest & Match Two \\
\hline
\end{tabular}

PCs as displayed on a standard monitor or on a projector screen. A Microsoft Access database was used to manage the information. Both hardware and software were verified to demonstrate the effectiveness of our system in the authors' paper. ${ }^{32}$ Readers are advised to refer to Chang et $\mathrm{al}^{32}$ for the details of the system operation.

\section{Data sources and measures}

We designed a survey to characterize the satisfaction level of the participants in using games for shoulder rehabilitation. The survey contained ten statements, as shown in Table S2. Each statement was measured using a five-point Likert scale, with the lowest value of 1 meaning "strongly disagree" and the highest value of 5 meaning "strongly agree." After all of the surveys were completed and collected, the scores for each statement were computed.

For the paper-and-pencil survey, the system functionalities were briefly explained and demonstrated to familiarize the respondents with the system operation. The participants were asked to rotate the homemade shoulder wheel ten times in clockwise and counterclockwise directions to obtain a feeling for how a conventional shoulder wheel works. After a short break, the participants engaged in hands-on operation of the rehabilitation system. They accessed the specific games according to gender and age, and they then played around with the system. After a treatment session, they were advised to fill out a form on which they indicated what they thought of or how they felt about the system. 


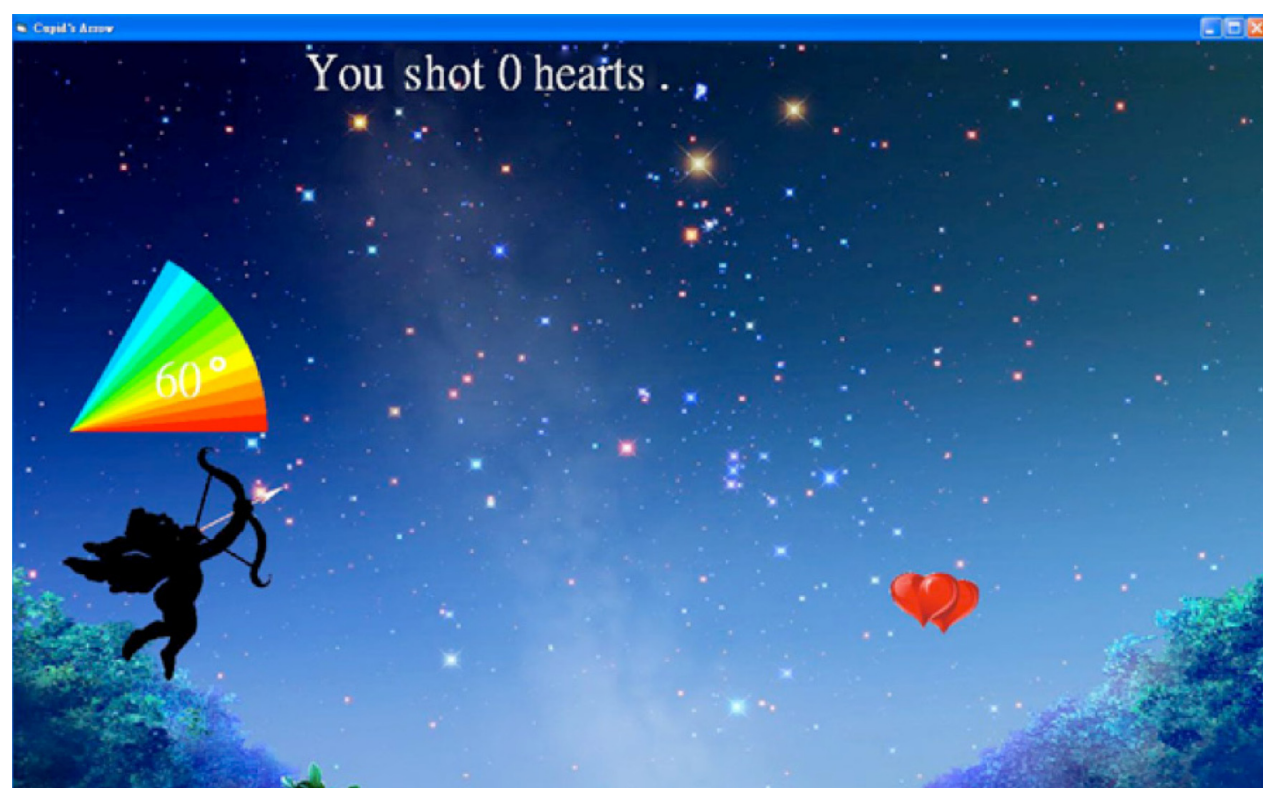

Figure 3 Screenshot of "Cupid's Arrow" game.

A website was set up to collect more feedback from a large number of respondents for the evaluation of the performance of our rehabilitation system. The system operation procedures for distinct games were videotaped and converted into MPEG-4 format files that were posted online for the public to retrieve through streaming media technology. After viewing the operation procedures, the visitor was guided to the webpage of an online survey and was asked to fill out a survey form.

\section{Data analysis}

Four variables were considered in this study: the survey method, game type, gender differences, and age of participants. These variables were analyzed via factorial experiments. The relationships of gender and age with the responses of the paper-and-pencil as well as the online surveys were separately evaluated. All analyses were conducted through the use of the Statistical Package for the Social Sciences (SPSS) 13.0 statistical program (IBM Corporation, Armonk, NY). Duncan's multiple range test was employed to determine the significant differences between the various factors. The statistical significance was determined at a significance level of $P<0.05$

\section{Results}

\section{Sample characteristics}

A paper-and-pencil survey was administered among 68 healthy participants, with 38 males and 30 females. Table 2 indicates the number of participants in each group and the corresponding distribution ratio. In the online survey, a total of 531 subjects participated, with 287 males and 244 females. Table 3 presents the related information for the online survey.

\section{Gender factor}

Significant differences were observed in the gender factor for the paper-and-pencil survey $\left(\mathrm{F}_{(1,628)}=7.943, P=0.005\right)$. In all survey statements, the satisfaction level of female participants (mean $4.30 \pm 0.045$ ) was higher than that of male participants (mean $4.05 \pm 0.042$ ). The female users found it easier to accept this new approach for rehabilitation. Statement 2 (Table S2) obtained the lowest score (mean $3.94 \pm 0.096$ ) for both genders, which indicated that the participants did not entirely enjoy the immersion in the game environment.

\section{Age factor}

Significant differences were observed between different age groups $\left(\mathrm{F}_{(2,628)}=6.575, P=0.001\right)$. The participants could be divided into two subgroups via Duncan's multiple range

Table 2 The participants of each group for the paper-and-pencil survey

\begin{tabular}{llll}
\hline Group number & Males & Females & $\begin{array}{l}\text { Ratio of participants } \\
(\mathbf{n}=\mathbf{6 8})\end{array}$ \\
\hline $\mathrm{GI}$ & 7 & 8 & $22 \%$ \\
$\mathrm{G} 2$ & 18 & 7 & $37 \%$ \\
$\mathrm{G} 3$ & 13 & 15 & $41 \%$ \\
\hline
\end{tabular}

Note: GI, under I 4 years; G2, I4-45 years; G3, over 45 years. 
Table 3 The participants of each group for the online survey

\begin{tabular}{llll}
\hline Group number & Males & Females & $\begin{array}{l}\text { Ratio of participants } \\
(\mathbf{n}=\mathbf{5 3} \text { I) }\end{array}$ \\
\hline GI & 63 & 64 & $24 \%$ \\
G2 & 134 & 113 & $47 \%$ \\
G3 & 90 & 67 & $29 \%$ \\
\hline
\end{tabular}

Note: GI, under 14 years; G2, I4-45 years; G3, over 45 years.

test. G2 had a relatively lower score (mean $3.94 \pm 0.047)$. No significant statistical differences were observed between $\mathrm{G} 1$ (mean 4.35 \pm 0.069 ) and G3 (mean 4.26 $\pm 0.048 ; P=0.252$ ). G2 participants expected more from this gaming system. G1 participants provided lower scores for statement 5 (Table S2) (mean $3.73 \pm 0.228$ ), showing they had greater doubts about the functionalities of our system when compared with those of a traditional shoulder wheel.

\section{Relationship between paper-and-pencil survey and online survey}

Statistical results indicated that for all statements, the scores of the online survey were higher than those of the paper-andpencil survey. Although differences were observed between the two survey methods $\left(\mathrm{F}_{(1,5915)}=233.575, P<0.00\right)$, the trends indicated by both surveys were similar. This finding suggests that the results of the paper-and-pencil survey coincide with those of the online survey.

The interaction between gender and age indicated that participants of different genders and age groups favored specific game types. This finding can be observed from the results of the male participants in G2 (mean $3.77 \pm 0.053$ ). No significant difference was observed in the interaction between gender and statement $\left(\mathrm{F}_{(9,628)}=0.281, P=0.980\right)$, which suggested the coinciding feelings of both male and female participants regarding the system.

\section{Discussion}

The scores of all groups across the ten statements ranged from $3.61 \pm 0.61$ to $4.86 \pm 0.38$. Most of the scores were above 4.0. These results indicated that most of the participants were satisfied with the game design, system operation, and expected rehabilitation effects of the mechanism we developed. After using this system, the respondents felt more relaxed than after operating a conventional shoulder wheel.

Examining the data for each gender and age group, the scores for males in the ages 14-45 group were slightly lower than those of the other groups (mean $3.83 \pm 0.71$ ). We speculate that this age range is too broad for only one game to satisfy all players. A possible solution would be to divide this group into subgroups. We would also consider providing a wider range of games to fit the distinct needs of each age group. For example, both genders in the ages 14-45 group commented on the contents of the game, and those above 45 responded on feeling physically present in the game environment.

In addition, participants in G1 (under 14 years) gave lower scores on the statement, "This system has the same therapeutic effect as the traditional one." We assumed that several respondents were too young (ages 6 and 7) to understand the statements, and they might not have ever seen an actual shoulder wheel, much less know how it works. We may need to provide further system orientation for this group before asking them to fill out the survey in the future.

\section{Conclusion}

Video games have been used as a form of physiological or occupational therapy in a number of studies. A game can motivate a patient to engage in the virtual world and provide a distraction from pain or anxiety. In this study, a gaming system was constructed for shoulder rehabilitation. The mechanism was designed to simulate the functionalities of an existing shoulder wheel. The control module was designed to capture the movements of the shoulder wheel and transmit the signals to a game on a PC platform. The game categories were designed according to the gender and age of the players. The statistical analysis based on the results of a paper-and-pencil and an online survey indicates the efficacy of our gaming system.

Most existing rehabilitation systems provide only one game for a specific application for all potential patients. We observed the gender and age differences and divided the subjects into six groups. Each group had its own favorite choice. Given that one game may not meet all the needs of the participants, each group could select from a wide range of game titles. The patients in each group could then have more choices instead of playing only the default game.

The development of treatment strategies requires a clear understanding of the ability and motivation of patients to participate in the therapy. This gaming system can distract a patient from pain or anxiety and increase their motivation for participating in this type of rehabilitation. The system is not intended to replace therapists, but it is meant as a tool by which to assist in monitoring the patient's progress and to ensure that the treatment plan is running smoothly. The advantage of its low cost makes our system suitable for use by patients at home. With minor modification, our system can also be integrated into a real shoulder wheel. Moreover, this design can be applied to other existing rehabilitation facilities. 


\section{Acknowledgments}

The authors would like to thank Bing-Yu Hsiao for conducting the surveys.

\section{Disclosure}

The authors report no conflicts of interest in this work.

\section{References}

1. van der Heijden GJ. Shoulder disorders: a state-of-the-art review. Baillieres Best Pract Res Clin Rheumatol. 1999;13(2):287-309.

2. Shoulder Pain. Seattle, WA: International Association for the Study of Pain; 2009. Available from: http://www.iasp-pain.org/AM/AMTemplate. $\mathrm{cfm}$ ? Section $=$ HOME $\&$ CONTENTID $=9293 \&$ SECTION $=\mathrm{HO}$ ME\&TEMPLATE $=/ \mathrm{CM} /$ ContentDisplay.cfm. Accessed March 15, 2012.

3. Ginn KA, Cohen ML. Exercise therapy for shoulder pain aimed at restoring neuromuscular control: a randomized comparative clinical trial. J Rehabil Med. 2005;37(2):115-122.

4. Kibler WB, McMullen J, Uhl T. Shoulder rehabilitation strategies, guidelines, and practice. Oper Tech Sports Med. 2000;8(4):258-267.

5. O'Sullivan SB, Schmitz TJ. Physical Rehabilitation. 5th ed. Philadelphia: F.A. Davis Company; 2007.

6. Burdea G. Virtual rehabilitation--benefits and challenges. Methods Inf Med. 2003;42(5):519-523.

7. Griffiths M. Video games and health. BMJ. 2005;331(7509):122-123.

8. Deutsch JE, Lewis JA, Burdea G. Technical and patient performance using a virtual reality-integrated telerehabilitation system: preliminary finding. IEEE Trans Neural Syst Rehabil Eng. 2007;15(1):30-35.

9. Halton J. Virtual rehabilitation with video games: a new frontier for occupational therapy. Occupational Therapy Now. 2008;9(6):12-14.

10. Adamovich S, Fluet GG, Merians AS, Mathai A, Qiu Q. Recovery of hand function in virtual reality: training hemiparetic hand and arm together or separately. Conf Proc IEEE Eng Med Bio Soc. 2008;2008:3475-3478.

11. Merians AS, Fluet GG, Qiu Q, Adamovich SV. Robotically facilitated training of the hemiparetic upper extremity as an integrated functional unit in virtual environments. International Conference on Virtual Rehabilitation (ICVR). 2009:185-188.

12. Guberek R, Schneiberg S, McKinley P, Cosentino F, Levin MF, Sviestrup H. Virtual reality as adjunctive therapy for upper limb rehabilitation in cerebral palsy. International Conference on Virtual Rehabilitation (ICVR). 2009:219.

13. Zhao R. Computer augmented rehabilitation using games and virtual reality environments. Long Island Business News; 2009. Available from: http://powstudios.com/system/files/LIBN_Computer_Augmented_ Rehab.pdf. Accessed October 21, 2012.

14. Watters C, Oore S, Shepherd M, et al. Extending the use of games in health care. The 39th Hawaii International Conference on Systems Science (HICSS-39 2006). 2006:88b.

15. Morrow K, Docan C, Burdea G, Merians A. Low-cost virtual rehabilitation of the hand for patients post-stroke. 2006 International Workshop on Virtual Rehabilitation (IWVR). 2006:6-10.

16. Raichur A, Wihardjo G, Banerji S, Heng J. A step towards home-based robotic rehabilitation: an interface circuit for EEG/SEMG actuated orthosis. IEEE/ASME International Conference on Advanced Intelligent Mechatronics. 2009:1998-2003.
17. Burke JW, Morrow PJ, McNeill MDJ, McDonough SM, Charles DK. Vision based games for upper-limb stroke rehabilitation. International Conference on Machine Vision and Image Processing (IMVIP 2008). 2008:159-164.

18. Ramchandani A, Carroll K, Buenaventura R, Douglas J, Liu J. Wii-habilitation increases participation in therapy. 2008 Virtual Rehabilitation. 2008:69.

19. Chen X, Ma C, He J, Xiao Z. Networking telemedicine in portable rehabilitation robot monitor system. Available from: http://citeseerx. ist.psu.edu/viewdoc/download?doi=10.1.1.121.7778\&rep=rep1\&type $=$ pdf. Accessed October 21, 2012.

20. Burke JW, McNeill MDJ, Charles DK, Morrow PJ, Crosbie JH, McDonough SM. Optimising engagement for stroke rehabilitation using serious games. Visual Computer. 2009;25(12):1085-1099.

21. Ryan M, Smith S, Chung B, et al. Rehabilitation Games: Designing Computer Games for Balance Rehabilitation in the Elderly. Available from: http://oscarmak.net/fdg09.pdf. Accessed October 21, 2012.

22. 3D Creativity: Real and Virtual [webpage on the Internet]. Project brief 1: games design - the rehabilitation game. Magee J. Available from: http://justinmagee.com/Project-Brief-1-Games-Design-TheRehabilitation-Game. Accessed March 15, 2012.

23. Entertainment Software Rating Board. ESRB ratings guide [webpage on the Internet]. New York: Entertainment Software Rating Board. Available from: http://www.esrb.org/ratings/ratings_guide.jsp. Accessed October 21, 2012.

24. Brain $\mathrm{Age}_{\mathrm{TM}}^{2}$ [homepage on the Internet]. Nintendo; 2007. Available from: http://www.brainage.com/launch/index.jsp. Accessed March 15, 2012.

25. Allstate examines brain fitness program to improve driver safety [webpage on the Internet]. Northbrook, IL: Allstate Insurance Company; 2008. Available from: http://www.allstatenewsroom.com/channels/ news-releases-auto/releases/allstate-examines-brain-fitness-programto-improve-driver-safety. Accessed March 15, 2012.

26. Hartmann T, Klimmt C. Gender and computer games: exploring females' dislikes. J Comput Mediat Commun. 2006;11(4):910-931.

27. Miller L, Chaika M, Groppe L. Girls' preferences in software design: insights from a focus group. Interpersonal Computing and Technology. 1996;4(2):27-36.

28. Phillips A. Soapbox: ARGs and how to appeal to female gamers [webpage on the Internet]. San Francisco, CA: UBM TechWeb; 2005. Available from: http://www.gamasutra.com/features/20051129/ phillips_01.shtml. Accessed March 15, 2012.

29. Agosto DE. Girls and Gaming: A Summary of the Research with Implications for Practice. New Brunswick, NJ: Rutgers University; 2003. Available from: http://girlstech.douglass.rutgers.edu/PDF/ GirlsAndGaming.pdf. Accessed March 15, 2012.

30. Shoulder wheels and pulleys [webpage on the Internet]. Lodi, OH: Bailey Manufacturing Company; 2012. Available from: http://www. baileymfg.com/products/exercisedevices/shoulderwheel/index.htm. Accessed October 21, 2012.

31. iResearch Consulting Group. China Online Game Research Report 2006. iResearch Inc; 2007. Available from: http://www.apira.org/data/ upload/pdf/Asia-Pacific/iResearch/iResearch0706282.pdf. Accessed October 21, 2012.

32. Chang CM, Chang YC, Hsiao BY. The design of a shoulder rehabilitation game system. IET International Conference on Frontier Computing: Theory, Technologies and Applications (IET FC10). 2010:151-156. 


\section{Supplementary materials}

Table SI Brief description of each game title in our system

\begin{tabular}{|c|c|}
\hline Game title & Description \\
\hline Submarine Hunter & $\begin{array}{l}\text { Submarines show up randomly under the water. A player can control a warship's position horizontally to throw bombs to } \\
\text { destroy them. }\end{array}$ \\
\hline Trebuchet & $\begin{array}{l}\text { Carts appear randomly in the desert. A player can adjust the projection power of the trebuchet to propel a stone to attack } \\
\text { them at distinct distances. }\end{array}$ \\
\hline Treasure Chest & $\begin{array}{l}\text { The secret code of a single-dial lock to open a treasure chest is shown at the top of the screen. A player can turn the dial } \\
\text { clockwise/counterclockwise to the appropriate spots to open the box. }\end{array}$ \\
\hline Cockroach Buster & Cockroaches show up on the left of the screen. A player can guide a little girl vertically to throw her slipper to smash them. \\
\hline Cupid's Arrow & $\begin{array}{l}\text { Bend Cupid's bow and point at hearts in the sky. A player can adjust the bow to an appropriate angle of attack and release } \\
\text { the string to shoot the hearts. }\end{array}$ \\
\hline Match Two & $\begin{array}{l}\text { Twelve cards with six pairs of fruit are shown and covered rapidly. A player has to memorize the locations of them. The } \\
\text { player then has to rotate the shoulder wheel to move to the appropriate locations and flip two cards consecutively to see } \\
\text { if there is a match. }\end{array}$ \\
\hline
\end{tabular}

Table S2 The questionnaire statements

\begin{tabular}{|c|c|}
\hline $\begin{array}{l}\text { Statement } \\
\text { number }\end{array}$ & Statement \\
\hline SI & You are interested in the contents of the game. \\
\hline S2 & You feel physically present in the game environment. \\
\hline S3 & The progress of the game is appropriate. \\
\hline S4 & The gaming system is easy to operate. \\
\hline S5 & $\begin{array}{l}\text { The gaming system has the same therapeutic effect as } \\
\text { the traditional one. }\end{array}$ \\
\hline S6 & $\begin{array}{l}\text { Playing the system makes you feel more relaxed than } \\
\text { operating a conventional shoulder wheel. }\end{array}$ \\
\hline S7 & $\begin{array}{l}\text { Playing the game can divert your attention and help } \\
\text { you forget the uncomfortableness. }\end{array}$ \\
\hline S8 & $\begin{array}{l}\text { You can focus on playing the game, and therefore the } \\
\text { effectiveness of treatment can be improved. }\end{array}$ \\
\hline S9 & $\begin{array}{l}\text { The rehabilitation progress is under control using this } \\
\text { gaming system. }\end{array}$ \\
\hline SIO & Overall, you are satisfied with this gaming system. \\
\hline
\end{tabular}

Patient Preference and Adherence

\section{Publish your work in this journal}

Patient Preference and Adherence is an international, peer-reviewed, open access journal focusing on the growing importance of patient preference and adherence throughout the therapeutic continuum. Patient satisfaction, acceptability, quality of life, compliance, persistence and their role in developing new therapeutic modalities and compounds to optimize clinical outcomes for existing disease states are major areas of interest. This journal has been accepted for indexing on PubMed Central. The manuscript management system is completely online and includes a very quick and fair peer-review system. Visit http://www.dovepress.com/ testimonials.php to read real quotes from published authors. 